\title{
Favorable response to pembrolizumab after durvalumab failure in a stage III sarcomatoid carcinoma of the lung: a case report
}

\author{
Kazumi Nishino*, Kei Kunimasa, Madoka Kimura, Takako Inoue, Motohiro Tamiya, Hanako Kuhara and \\ Toru Kumagai
}

\begin{abstract}
Background: Pulmonary sarcomatoid carcinoma is a rare non-small-cell lung cancer (NSCLC) subtype with a poor prognosis. In the phase III PACIFIC study, durvalumab significantly improved progression-free survival and overall survival versus placebo, in patients with stage III NSCLC who do not have disease progression after concurrent chemoradiotherapy. However, treatments for patients who discontinue durvalumab due to disease progression, are unknown.

Case presentation: We report a case of favorable response to pembrolizumab in a patient with disease progression during durvalumab consolidation therapy after chemoradiotherapy for stage III pulmonary sarcomatoid carcinoma with high programmed cell death ligand 1 (PD-L1) and PD-L2 expression.

Conclusion: Here, we present what, to the best of our knowledge, is the first reported case in which durvarumab resistance after definitive chemoradiotherapy in a patient with stage III pulmonary sarcomatoid carcinoma was overcome by pembrolizumab.
\end{abstract}

Keywords: Pulmonary sarcomatoid carcinoma, Durvalumab, Pembrolizumab, PD-L1, PD-L2

\section{Background}

Pulmonary sarcomatoid carcinoma (SC) is a rare subtype of non-small-cell lung cancer (NSCLC), accounting for approximately 0.1 to $0.4 \%$ of all lung cancer cases [1]. SC is a general term that includes pleomorphic carcinoma, spindle cell carcinoma, giant cell carcinoma, carcinosarcoma, and pulmonary blastoma [2]. SC shows highly aggressive biological behaviors associated with a poor prognosis and high resistance to chemotherapy [3, 4]. SC shows high levels of programmed death ligand-1 (PD-L1) [5, 6], and it has recently been reported that immune checkpoint inhibitors (ICIs) are very effective. Most ICIs are PD-1 inhibitors such

\footnotetext{
* Correspondence: nisino-ka@mc.pref.osaka.jp

Department of Thoracic Oncology, Osaka International Cancer Institute, 3-1-69 Otemae Chuo-ku, Osaka 541-8567, Japan
}

as nivolumab and pembrolizumab [7]. In the phase III PACIFIC study, durvalumab significantly improved progression-free survival (PFS) and overall survival (OS) versus placebo, in patients with stage III without disease progression after concurrent chemoradiotherapy [8, 9]. Following discontinuation of durvalumab, 195 patients $(41.0 \%)$ received subsequent anticancer therapy. Most patients subsequently received cytotoxic chemotherapy, and only 38 patients $(8.0 \%)$ received additional immunotherapy [9]. No results have been reported for the subsequent treatment. We herein report the use of pembrolizumab in the setting of disease progression during durvalumab consolidation therapy after chemoradiotherapy in a patient with stage III SC with high PD-L1 expression.

C C The Author(s). 2020 Open Access This article is licensed under a Creative Commons Attribution 4.0 International License, which permits use, sharing, adaptation, distribution and reproduction in any medium or format, as long as you give appropriate credit to the original author(s) and the source, provide a link to the Creative Commons licence, and indicate if changes were made. The images or other third party material in this article are included in the article's Creative Commons licence, unless indicated otherwise in a credit line to the material. If material is not included in the article's Creative Commons licence and your intended use is not permitted by statutory regulation or exceeds the permitted use, you will need to obtain permission directly from the copyright holder. To view a copy of this licence, visit http://creativecommons.org/licenses/by/4.0/ The Creative Commons Public Domain Dedication waiver (http://creativecommons.org/publicdomain/zero/1.0/) applies to the data made available in this article, unless otherwise stated in a credit line to the data. 


\section{Case presentation}

A 62-year-old healthy asymptomatic male currentsmoker presented with an abnormal shadow on chest radiography during a regular health check-up. A computed tomography (CT) scan showed a mass in the right upper lobe. Transbronchial lung biopsy pathology confirmed SC. The lung biopsy specimens were negative for $\mathrm{p} 40$, thyroid transcription factor 1 , and calretinin, and positive for cytokeratin AE1/3. The patient was diagnosed with stage IIIA (cT3N1M0) SC in May 2018. Molecular testing revealed no targetable mutations. Immunohistochemical staining of the tumor tissue showed PD-L1 expression in $90 \%$ of the tumor. The patient was treated with two cycles of concurrent vinorelbine $\left(20 \mathrm{mg} / \mathrm{m}^{2}\right.$ on days 1 and 8$)$ plus cisplatin ( $5 \mathrm{mg} / \mathrm{m}^{2}$ on day 1 ) and definitive $60 \mathrm{~Gy}$ of thoracic radiation therapy. He showed a partial response to treatment at the primary tumor site and received durvalumab at $10 \mathrm{mg} / \mathrm{kg}$ every 2 weeks. Three months later, in November 2018, disease progression was detected by $18 \mathrm{~F}$-fluorodeoxyglucose-positron emission tomography, which showed new metastases in the left lung, abdominal lymph nodes, and left psoas. He had undergone seven cycles of durvalumab.

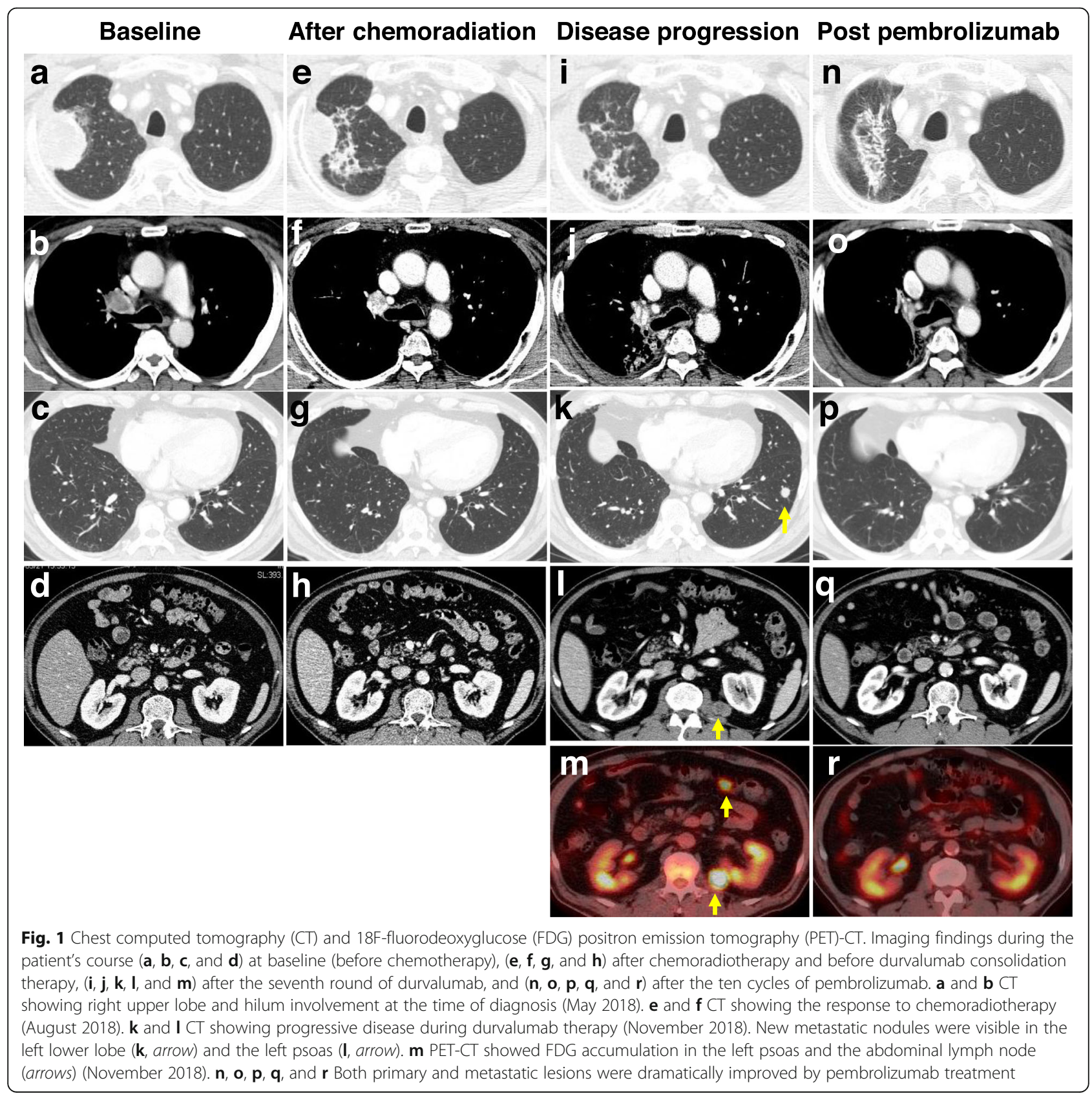


He immediately received pembrolizumab at $200 \mathrm{mg} /$ body every 3 weeks, because of the high expression of PD-L1 in the tumors. After two cycles of pembrolizumab, CT revealed a durable clinical response in December 2018. The patient has subsequently achieved complete tumor response in June 2019 (Fig. 1).

We analyzed the PD-L2 expression, and immunofluorescence double-staining showed high expression of PDL1 and PD-L2 in the tumor tissue (Fig. 2, Supplementary methods of Fig. 2).

\section{Discussion and conclusions}

The case presented herein adds valuable insights into the use of pembrolizumab in the setting of disease progression during durvalumab consolidation therapy after chemoradiotherapy in a patient with stage III SC with high PD-L1 expression.

The primary site in the right lung was reduced markedly, but three new metastatic lesions appeared during durvalumab treatment (Fig. 1). This case was clearly considered a progressive disease. The results of PACIFIC phase III trial are expected to establish durvalumab, a selective PD-L1 inhibitor, as the standard consolidation strategy in patients with unresectable stage III NSCLC without disease progression after concurrent chemoradiotherapy [8, 9]. Exploratory post-hoc analyzes showed that the benefits of PFS and OS in the durvalumab group were evident in patients with a PD-L1 tumor proportion score of $25 \%$ or greater before chemoradiation. PD-L1 expression of $\geq 25 \%$ on tumor cells occurred in $24.2 \%$ of patients in the durvalumab group, but the proportion of PDL1 expression in $\geq 50 \%$ of tumor cells is unknown. Currently, as a result of the KEYNOTE-024 trial results, pembrolizumab, a selective PD-1 inhibitor, is administered as first-line treatment for patients with advanced NSCLC with PD-L1 expression on $\geq 50 \%$ of tumor cells [10]. One of the reasons that the efficacy of pembrolizumab is improved compared to durvalumab is the essential difference between anti-PD-1 and anti-PD-L1. Duan J. et al. performed meta-analysis and suggests that anti-PD-1 exhibited favorable survival outcomes and a safety profile comparable to that of anti-PD-L1 [11]. Pembrolizumab binds PD-1 and blocks the PD-1-PD-L1/PD-L2 axis. In contrast, durvalumab selectively blocks PD-L1 binding to PD-1 and CD80 without inhibiting PD-L2. Therefore, the interaction of $\mathrm{PD}-1$ and $\mathrm{PD}-\mathrm{L} 2$ remain intact and may inhibit $T$ cell activation. In a recent report of patients with NSCLC treated with anti-PD-1 antibodies, both PD-L1 and PD-L2 positivity potentially predicted clinical response to anti-PD-1 therapy [12].

In the PACIFIC trial, $52.9 \%$ of the patients in the durvalumab group had a nonsquamous histologic type of tumor, but no cases of SC were reported. SC shows highly aggressive behavior and resistance to chemotherapy [3, 4]. Recent studies report that SC shows high levels of PD-L1 [5], tumor mutation burden and strong immune-cell infiltration [6]. We suspected pleomorphic carcinoma in this case because of the histologic components of spindle and giant cells, although there was limited biopsy tissue. Pulmonary pleomorphic carcinomas very frequently express both PD-L1 and PD-L2 [13]. This case had high PD-L1/ PD-L2 expression on tumor cells (Fig. 2). Therefore, targeting the PD-1-PD-L1/PD-L2 pathway may represent a potential therapeutic candidate for this type of aggressive tumor after failure of durvalumab. In conclusion, pembrolizumab may be an option for treatment to durvalumab resistance after definitive chemoradiotherapy in a patient with stage III SC with high PD-L1 and PD-L2 expression. Of course, this case is only one case, so we cannot assert it and more cases are needed.

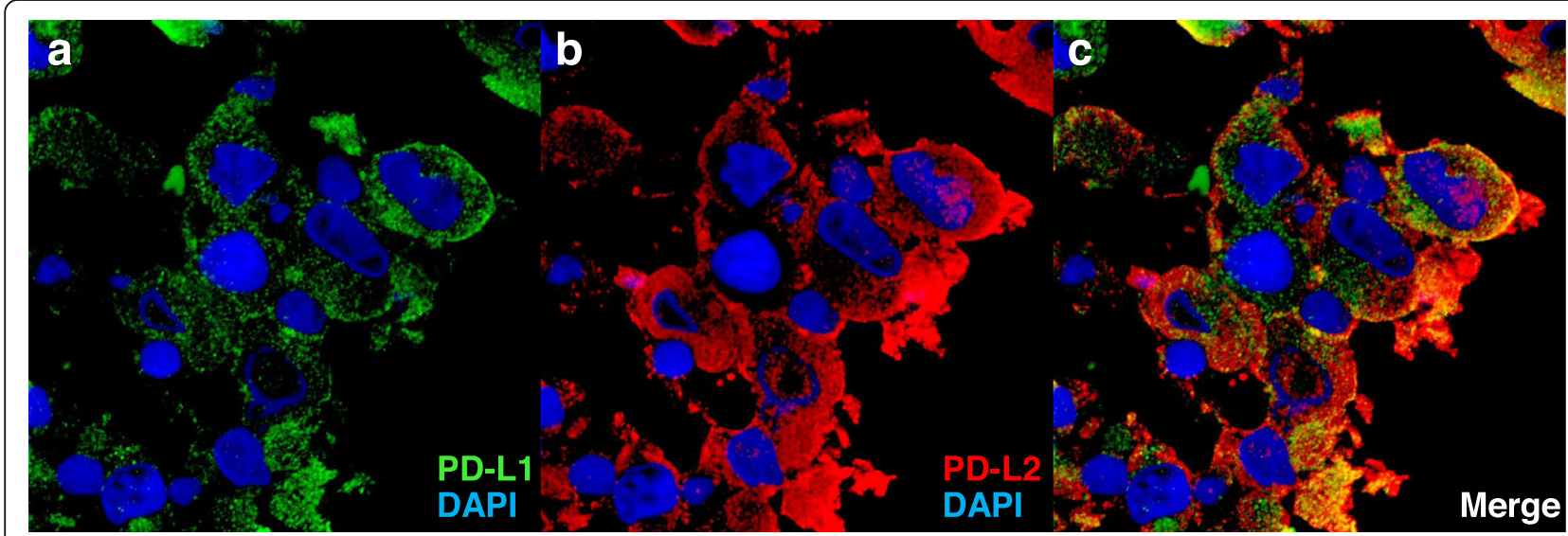

Fig. 2 Immunofluorescence analysis of programmed cell death ligand 1 (PD-L1) and PD-L2 expression. The panels show fluorescence captions of PD-L1 (a, green) and PD-L2 (b, red) positivity of the same sample (c). Nuclei were stained with 4', 6-diamidino-2-phenylindole (blue) 


\section{Supplementary information}

Supplementary information accompanies this paper at https://doi.org/10. 1186/s40360-020-00404-7.

Additional file 1. Supplementary methods of Fig. 2 The methods of Immunofluorescence analysis of PD-L1 and PD-L2 expression.

\section{Abbreviations}

SC: Sarcomatoid carcinoma; NSCLC: Non-small-cell lung cancer; PD-

L1: Programmed cell death ligand 1; PD-L2: Programmed cell death ligand 2;

CT: Computed tomography; PFS: Progression-free survival; OS: Overall survival

\section{Acknowledgements}

We particularly thank the patient for consenting to share the details of this case.

\section{Authors' contributions}

$\mathrm{KN}, \mathrm{KK}, \mathrm{MK}, \mathrm{TI}, \mathrm{HK}, \mathrm{MT}$, and $\mathrm{KT}$ performed the clinical diagnosis and discussed treatment policy. KK performed the immunofluorescent experiments. All authors read and approved the final manuscript.

\section{Funding}

No funding sources to report.

\section{Availability of data and materials}

All data are contained within the manuscript.

\section{Ethics approval and consent to participate}

According to Norwegian regulations no ethics approval was required for this case report.

\section{Consent for publication}

Written and verbal consent from the patient has been obtained. As stated in the instructions, a consent form has not been included on submission but is available for request.

\section{Competing interests}

KN received honoraria from AstraZeneca and MSD. KK received honoraria from AstraZeneca. TI received honoraria from AstraZeneca and MSD. MT received honoraria from AstraZeneca and MSD. TK received from AstraZeneca and MSD. All the others declare that they have no conflict of interest.

Received: 23 June 2019 Accepted: 18 March 2020

Published online: 03 April 2020

\section{References}

1. Yendamuri S, Caty L, Pine M, Adem S, Bogner P, Miller A, et al. Outcomes of sarcomatoid carcinoma of the lung: a surveillance, epidemiology, and end results database analysis. Surgery. 2012;152(3):397-402.

2. Travis WD, Brambilla E, Nicholson AG, Yatabe Y, Austin JHM, Beasley MB, et al. The 2015 World Health Organization classification of lung tumors: impact of genetic, clinical and radiologic advances since the 2004 classification. J Thorac Oncol. 2015;10(9):1243-60.

3. Vieira T, Girard N, Ung M, Monnet I, Cazes A, Bonnette P, et al. Efficacy of first-line chemotherapy in patients with advanced lung sarcomatoid carcinoma. J Thorac Oncol. 2013;8(12):1574-7.

4. Ung M, Rouquette I, Filleron T, Taillandy K, Brouchet L, Bennouna J, et al. Characteristics and clinical outcomes of Sarcomatoid carcinoma of the lung. Clin Lung Cancer. 2016;17(5):391-7.

5. Velcheti V, Rimm DL, Schalper KA. Sarcomatoid lung carcinomas show high levels of programmed death ligand-1 (PD-L1). J Thorac Oncol. 2013;8(6): 803-5.

6. Vieira T, Antoine M, Hamard C, Fallet V, Duruisseaux M, Rabbe N, et al. Sarcomatoid lung carcinomas show high levels of programmed death ligand-1 (PD-L1) and strong immune-cell infiltration by TCD3 cells and macrophages. Lung Cancer. 2016:98:51-8.

7. Domblides C, Leroy K, Monnet I, Mazieres J, Barlesi F, Gounant V, et al. Efficacy of immune checkpoint inhibitors in lung Sarcomatoid carcinoma. J Thorac Oncol. 2020. [Epub ahead of print].
8. Antonia SJ, Villegas A, Daniel D, Vicente D, Murakami S, Hui R, et al. Durvalumab after Chemoradiotherapy in stage III non-small-cell lung Cancer. N Engl J Med. 2017;377(20):1919-29.

9. Antonia SJ, Villegas A, Daniel D, Vicente D, Murakami S, Hui R, et al. Overall survival with Durvalumab after Chemoradiotherapy in stage III NSCLC. N Engl J Med. 2018;379(24):2342-50.

10. Reck M, Rodriguez-Abreu D, Robinson AG, Hui R, Csoszi T, Fulop A, et al. Pembrolizumab versus chemotherapy for PD-L1-positive non-small-cell lung Cancer. N Engl J Med. 2016:375(19):1823-33.

11. Duan J, Cui L, Zhao X, Bai H, Cai S, Wang G, et al. Use of immunotherapy with programmed cell death 1 vs programmed cell death ligand 1 inhibitors in patients with Cancer: a systematic review and meta-analysis. JAMA Oncol. 2019;26. [Epub ahead of print].

12. Takamori S, Takada K, Toyokawa G, Azuma K, Shimokawa M, Jogo T, et al. PD-L2 expression as a potential predictive biomarker for the response to anti-PD-1 drugs in patients with non-small cell lung Cancer. Anticancer Res. 2018;38(10):5897-901.

13. Kim S, Kim MY, Koh J, Go H, Lee DS, Jeon YK, et al. Programmed death-1 ligand 1 and 2 are highly expressed in pleomorphic carcinomas of the lung: comparison of sarcomatous and carcinomatous areas. Eur J Cancer. 2015; 51(17):2698-707

\section{Publisher's Note}

Springer Nature remains neutral with regard to jurisdictional claims in published maps and institutional affiliations.

\section{Ready to submit your research? Choose BMC and benefit from:}

- fast, convenient online submission

- thorough peer review by experienced researchers in your field

- rapid publication on acceptance

- support for research data, including large and complex data types

- gold Open Access which fosters wider collaboration and increased citations

- maximum visibility for your research: over $100 \mathrm{M}$ website views per year

At BMC, research is always in progress.

Learn more biomedcentral.com/submissions 